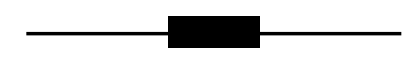

\title{
Introduction
}

\section{Dialogues and Trajectories}

In his luminous reflections on the intellectual trajectory that he has traced so far-beginning with the modern and proceeding through the secular toward the global-José Casanova notes that his evolving interests took him away from anthropology and toward sociology. Yet Casanova's work has remained influential on, and in conversation with, that of many anthropologists, not least as a result of his desire to transcend a "Western-centric view of history and human development" (this volume) as well as his predictions that Pentecostalism may well become the predominant form of Christianity in the twenty-first century. This second volume of Religion and Society presents Casanova-author of the classic Public Religions in the Modern World (1994) - in dialogue with his own past and shifting present, but also responding to the comments of scholars who are themselves anthropologically informed and yet able to represent perspectives from sociology, theology, and religious studies.

As noted in the introduction to the first volume in 2010, our hope as editors is that Religion and Society can provide the ideal forum for these kinds of encounters, in which the anthropology of religion can be represented as constituted through numerous intellectual trajectories, developed through debate rather than fixed in form or parochial in focus. Anthropology in dialogue with other ways of analyzing religion-and indeed the world-appears to be the theme of many of the contributions to this volume.

Ruth Marshall, the other scholar whose work is specifically highlighted in these pages, provides a distinctive, sophisticated, and powerful analytical voice, in part because she is able to straddle, both eloquently and critically, the worlds of anthropology and political science. Thus, some of the commentary on her volume Political Spiritualities: The Pentecostal Revolution in Nigeria (2009) dwells precisely on this question of the disciplinary character of the book: while it is clearly ethnographically informed, it is not an ethnography-nor is it meant to be. Marshall's refusal to conform to fixed intellectual categories, a stance that forms part of the dynamic of the book, has parallels with the character of Pentecostalism that emerges in the text. Its spiritual message is shown to have a deeply political content, but not one that can be consigned to or contained within mere party politics and therefore insulated from practices of power and the formation of subjectivity in other aspects of life in Nigeria. We should also remember that Marshall has lived and worked in European, North American, and African intellectual contexts, and the richness of her work must surely partake of some of this varied institutional experience.

The influence of national institutions on academic discourse (even in a 'global' age) is made still more explicit in another piece on the role of Christianity in public and political realms. The article by Cecília Mariz and Roberta Campos on Pentecostalism in Brazil reflects not only on the expansion of Pentecostalism in that country, but also on Pentecostalism as an object of scholarly discourse within Brazil. As such, it is implicated within politically inflected constructions of what is perceived to be 'national culture'. In this piece, the authors trace dialogues that are 
complex and fascinating: between generations of scholars of Pentecostalism, who see it as continuous with or fundamentally distinct from national culture; between a predominantly AngloSaxon construction of an anthropology of Christianity and a Brazilian take on the themes that are raised (not least those invoking the Weberian inheritance, which played an ambiguous part in Casanova's intellectual development); and between Brazilian interpretations of the role and constitution of sociology and anthropology as public as well as analytical discourses.

Ursula Rao's piece on 'inter-publics' in Hindu contexts in India has resonances with all of the works mentioned above. Written by an anthropologist, it is intended to be a contribution to Indian sociology, while emerging from a fieldwork context where the roles of anthropologist and sociologist again do not quite fit with those of Euro-American academia, as traditionally envisioned. Rao's notion of 'publics' as an analytical as well as descriptive tool is conceived in part as a challenge to the European, ideal-typical constructions of the public sphere as proposed by Jürgen Habermas, one of Casanova's intellectual interlocutors. And, as emerges very strongly in Rao's piece, there is clearly little point in attempting to separate the political from the religious in the porous and unstable interlinkings of the devotional practices, media productions, and political mobilizations that she describes.

In the previous volume, we included a number of pieces relating to the 'cognitive turn' that has been evident among some anthropologists of religion: Carles Salazar's review article was complemented by the different positions evident in our profile of Maurice Bloch's work as well as Emma Cohen's book The Mind Possessed. We are now creating a thematic dialogue across volumes, as two articles in this volume attempt, in different ways, to find a rapprochement between cognitive and other methodological and theoretical orientations in the anthropology of religion. Vlad Naumescu uses the theme of transmission to reflect on how to combine 'historicist' and 'universalist' stances, advocating a pragmatic approach that can link the material, contextual, and institutional dimensions of transmission with corresponding cognitive, perceptive, and emotional processes. The piece also provides some useful resonances with debates in other articles in this volume. Naumescu's focus on transmission and temporality takes us back to themes of rupture and discontinuity that we see not only in Weberian sociology but also debated in the work of Marshall, Mariz and Campos, and, very importantly, Joel Robbins, one of the commentators on Marshall's book. In addition, Naumescu provides us with some ethnography of Old Believers, an apocalyptic movement that emerged out of a schism in seventeenth-century Russian Orthodoxy, and therefore expands our purview of the anthropology of Christianity as reflected in this volume. Julia Cassaniti and Tanya Marie Luhrmann, meanwhile, present a nuanced and yet bold set of linkages, laying out a phenomenological approach that seeks to identify patterns in social expectations about religious experience. They take an experiential category of human life - the supernatural — and trace how it varies across cultural boundaries, thus looking at the implicit social rules around the way that experience is 'known' and 'felt'. For them, the concept of mind is key to an anthropological phenomenology, and in making their argument they quote yet another of Casanova's interlocutors, Charles Taylor (2007), who has famously described the Euro-American mind as 'buffered'.

Despite its recent emergence as the object of analysis of a powerful sub-field, Christianity has often been viewed as marginal to the anthropology of religion, either as a background and repressed 'noise' to proper fieldwork or as an embodiment of a repugnant other living all too close to home. Andrew Buckser provides us with an invaluable review of the developing anthropology of Judaism. In his depiction of how scholars have approached a religion that is often seen as inhabiting the edges, the diasporas of cultural worlds, he makes the concept of the margin a powerful analytical and ethnographic trope. In keeping with our wider aims for this journal, Buckser locates his analysis of interest in Judaism within a wider consideration of 
anthropological constructions of its object and, in the process, some of the ways in which this religion can be conceptualized in relation to those now familiar tropes of the modern, the secular, and the global.

Other contributions to this volume are shorter but remain vital to our presentation of an anthropology of religion in the making. In the debate section, the pieces on religion and violence deal with a topic of current (and perhaps perennial) interest, juxtaposing anthropological and theological perspectives in doing so. Here, part of the aim of the analysis is less to couple religious practice with what have often been presented as 'other' spheres of life, such as the political, than to complicate popular views that see the religious as inherently bound up with the violent. Collins and Egorova's article on teaching the anthropology of religion presents an intriguing way in which to bring students into the discipline: by using controversies and tensions that present religious discourse in motion, but also to hint-as part of the meta-message of the course-that anthropology itself has a role to play in contributing to public debate. The course is about to be taught, rather than a finished product, as seems fitting for a journal that attempts to capture the dynamism and dialogues that make up its sub-field. We conclude with sections on news and book and film reviews that provide a further glimpse into the activities of the present and perhaps some of the intellectual trajectories of the near future.

Simon Coleman and Ramon Sarró

\section{REFERENCES}

Casanova, José. 1994. Public Religions in the Modern World. Chicago: University of Chicago Press.

Marshall, Ruth. 2009. Political Spiritualities: The Pentecostal Revolution in Nigeria. Chicago: University of Chicago Press.

Taylor, Charles. 2007. A Secular Age. Cambridge, MA: Belknap Press. 

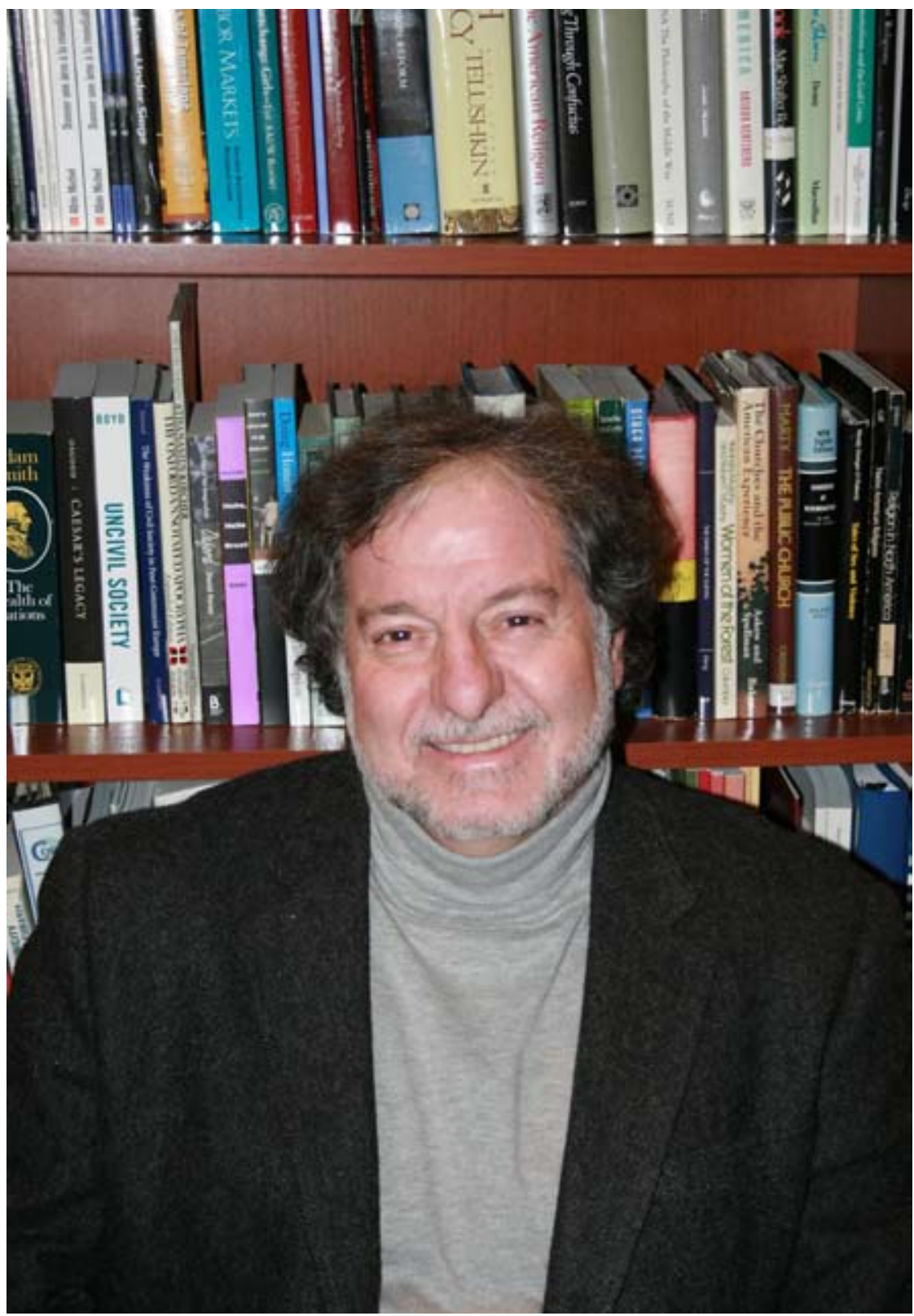

José Casanova 